\title{
Relational and social-cognitive correlates of early adolescents' forgiveness of parents
}

\author{
Katherine J. Christensen \\ Brigham Young University - Provo \\ Laura M. Padilla-Walker \\ Brigham Young University - Provo \\ Dean M. Busby \\ Brigham Young University - Provo, dean_busby@byu.edu \\ Sam A. Hardy \\ Brigham Young University - Provo \\ Randal D. Day

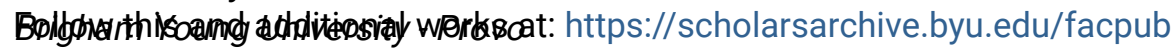 \\ Part of the Other Social and Behavioral Sciences Commons
}

\section{Original Publication Citation}

Christensen, K. J., Walker, L. M., Busby, D. M., Hardy, S. A., \& Day, R. D. (2011). Relational and social-cognitive correlates of early adolescents' forgiveness of parents. Journal of Adolescence, 34, 901-913.

\section{BYU ScholarsArchive Citation}

Christensen, Katherine J.; Padilla-Walker, Laura M.; Busby, Dean M.; Hardy, Sam A.; and Day, Randal D., "Relational and social-cognitive correlates of early adolescents' forgiveness of parents" (2011). Faculty Publications. 4611.

https://scholarsarchive.byu.edu/facpub/4611

This Peer-Reviewed Article is brought to you for free and open access by BYU ScholarsArchive. It has been accepted for inclusion in Faculty Publications by an authorized administrator of BYU ScholarsArchive. For more information, please contact ellen_amatangelo@byu.edu. 


\title{
Relational and social-cognitive correlates of early adolescents' forgiveness of parents
}

\author{
Katherine J. Christensen*, Laura M. Padilla-Walker, Dean M. Busby, Sam A. Hardy, \\ Randal D. Day \\ Brigham Young University, USA
}

Keywords:

Forgiveness

Adolescence

Parenting

Relationships

\begin{abstract}
A B S T R A C T
This study examined how mother and father-child relationship quality and marital forgiveness were related to early adolescents' forgiveness of mothers and fathers. Adolescents' social-cognitive skills (empathy and emotional regulation) and parents' forgiveness of child were examined as mediators. Mother, father, and child self-reported questionnaires and observational data were taken from Time 1 and Time 3 (two years later) of the Flourishing Families Project, and included 334 two-parent families with an early adolescent ( $M$ age at Time $1=11.24 ; 51 \%$ male; 76\% Caucasian). Using path analyses via structure equation modeling, mother-child relationship quality and adolescents' own social-cognitive skills were salient correlates of adolescents' forgiveness toward parents. The unique contributions of mothers and fathers, differences by reporter, and the importance of studying forgiveness within the parent-child relationship are discussed. () 2011 The Foundation for Professionals in Services for Adolescents. Published by Elsevier
\end{abstract} Ltd. All rights reserved.

\section{Relational and social-cognitive correlates of early adolescents' forgiveness of parents}

The process of forgiveness may be defined as the ability to treat an offender with love and beneficence, willfully abandoning the resentment and pain from an offense (see Klatt \& Enright, 2009; McCullough \& Witvliet, 2002). In this intra- and inter-individual process, the offended seeks to regulate personal emotions and thoughts and respond positively toward the offender (Rye \& Pargament, 2002; Sastre, Vinsonneau, Neto, Girard, \& Mullet, 2003). Although a complex construct in the empirical realm, forgiveness has been distinguished from similar constructs such as denial (being unwilling to perceive the offense), forgetting (removing the awareness of the offense), condoning (removing the offense and the need for forgiveness), and reconciliation (restoring the relationship regardless of forgiveness; Enright, Freedman, \& Rique, 1998; Fow, 1996; Kachadourian, Fincham, \& Davila, 2004; Sastre et al., 2003). The ability to forgive another and move from negative to positive thoughts, emotions, and behaviors is indeed a difficult process to not only accomplish, but also to study empirically. Yet it can yield a number of mental, emotional, and physiological benefits (see Witvliet, Ludwig, \& Van der Laan, 2001), as well as relational benefits such as restored relational harmony and healed emotional wounds (see McCullough \& Worthington, 1994; Paleari, Regalia, \& Fincham, 2003). Despite the complicated nature of forgiveness, most researchers agree that the primary influencing factors are cognitive, affective, and situational.

\footnotetext{
* Corresponding author. 2097 JFSB, School of Family Life, Brigham Young University, Provo, UT 84602, USA. Tel.: +1 7023586305 ; fax: +1 8014220230. E-mail address: kathy.j.christensen@gmail.com (K.J. Christensen).
} 
Recent research has also indicated that relational context may play a role in people's decisions to forgive, as closer relationships bring greater hurt from transgressions and more motivation to work to maintain the relationship (see Gold \& Davis, 2005). Close relationships will inherently include a shared history and emotional bonds that influence forgiving above and beyond a tendency to forgive in other situations (Kachadourian et al., 2004). One of the most prominent theories incorporating relational factors in forgiveness was presented by (McCullough et al (1998). In their social-psychological framework, personal, relational, and situational variables influence the most proximal determinants of forgiveness, such as empathy. However, the majority of research testing theories of interpersonal forgiveness has been done with dating and married couples (Gordon, Hughes, Tomcik, Dixon, \& Litzinger, 2009; Kachadourian et al., 2004). Little is known about forgiveness in parent-child relationships (see Maio, Thomas, Fincham, \& Carnelley, 2008; Paleari et al., 2003), even though research suggests that forgiveness may function differently in parent-child dyads than in marital dyads (Hoyt, Fincham, McCullough, Maio, \& Davila, 2005), and adolescence is a time of increased parent-child conflict (Sartor \& Youniss, 2002) wherein forgiveness may be particularly poignant. Forgiveness during adolescence may buffer the negative effects of parent-child conflict and reduce its frequency and severity (Paleari et al., 2003). Therefore, the purpose of this study was to use McCullough et al, (1998) social-psychological framework to examine what factors may be related to adolescents' disposition to forgive. Specifically, this two year longitudinal study examined how parent-child and marital relationships are related to the development of adolescent forgiveness, and whether adolescent social-cognitive skills and parental modeling are mediators of this process.

Parent-child relationship quality as a predictor of adolescent forgiveness

Studies on close adult relationships have indicated that the quality of the relationship is integral in determining forgiveness. For example, higher levels of couple attachment and commitment predict greater forgiveness within the relationship (Finkel, Rusbult, Kumashiro, \& Hannon, 2002; Kachadourian et al., 2004), and forgiveness occurs more readily in satisfactory, committed relationships (McCullough et al., 1998; McCullough, Worthington, \& Rachal, 1997). However, little work has explored the link between closeness and forgiveness in parent-child dyads (Denham, Neal, Wilson, Pickering, \& Boyatsis, 2005). An exception is a study by Paleari and colleagues (Paleari et al., 2003) which found a link between parent-child relationship quality and child forgiveness which was mediated by the child's social-cognitive traits, such as attributions and emotions. However, further research is needed examining the developmental processes linking parent-child relationship quality and adolescent forgiveness.

\section{Parental modeling}

Given the hierarchical nature of the parent-child relationship, other relational factors may influence the development of child forgiveness, such as modeling. Just as children learn behaviors such as emotional regulation and aggression by observing their parents (Conger, Neppl, Kim, \& Scaramella, 2003; Morris, Silk, Steinberg, Myers, \& Robinson, 2007), parental modeling of forgiveness within the marriage and parent-child relationship may also impact adolescent forgiveness (Maio et al., 2008; Mullet, Girard, \& Bakhshi, 2004; Subkoviak et al., 1995).

\section{Marital forgiveness}

Given research suggesting that modeling is critical for children to learn proper expression of anger and emotion in order to forgive (Murray, 2002), marital forgiveness may be linked to adolescents' forgiveness of their parents. This may occur through the acquisition of forgiveness-relevant social-cognitive skills, such as empathy. Also, those who are more forgiving of their spouse are expected to be more forgiving of their children because the tendency to forgive is grounded in relatively stable personality traits (McCullough and Hoyt, 2002), and positive family functioning in one dyad tends to resonate into other family dyads (Bowen, 1978).

\section{Parents' forgiveness of the child}

While parental forgiveness of the child appears to influence the adolescent's development of forgiveness, current research has yet to consider how the quality of the parent-child relationship may affect these processes. Within the parent-child dyad, closeness may facilitate a greater willingness of parents to forgive their child of transgressions. The child, after seeing and experiencing this forgiveness, may reciprocate by forgiving the parent. Given research classifying forgiveness as a prosocial behavior (McCullough et al., 1997), and research suggesting that children are more likely to emulate modeled behaviors from those with whom they have a close relationship (Bandura, 1986; Eisenberg \& Fabes, 1998), parental modeling of forgiveness may increase forgiveness in children if the parent-child relationship is positive. Thus, the current study will examine the direct and mediating role of mother and father forgiveness of the child on subsequent adolescent forgiveness of each parent.

\section{Social-cognitive mediators}

In addition to modeling behaviors, parents may help promote forgiveness in their children by fostering the acquisition of social-cognitive skills required to forgive. According to the social-psychological framework presented by McCullough and colleagues (McCullough et al., 1998), relational variables (e.g., closeness) indirectly influence forgiveness in close relationships 
through social-cognitive traits (e.g., attributions, ruminations, empathic emotions). Despite the limited research on forgiveness within the parent-child relationship specifically, research on other close relationships has indicated that empathy and emotional regulation may be salient mediators explaining the link between relationship quality and forgiveness.

\section{Empathy}

Empathy, or the ability to experience the emotions or feelings of others (Hodgson \& Wertheim, 2007), may be the most salient mediator between close adult relationship quality and forgiveness (Enright \& Fitzgibbons, 2000; Malcolm \& Greenberg, 2000). As explained by McCullough et al. (1997), empathy allows the victim to recognize the emotions such as distress, guilt, or loneliness experienced by the offender and motivates the victim to mend the estranged relationship through forgiveness. Research has also indicated that parents indirectly influence the development of prosocial behaviors through sympathy and empathy (see Eisenberg, Fabes, \& Spinrad, 2006; Hoffman, 2001). If forgiveness functions similarly to other prosocial behaviors, a close parent-child relationship may indirectly influence forgiveness through the promotion of socialcognitive skills such as empathy in the child.

\section{Emotional regulation}

In addition to empathy, adolescents' abilities to regulate emotions may also promote forgiveness. According to Rizkalla, Wertheim, and Hodgson (2008), forgiveness requires the ability to first be aware of personal emotions (e.g., emotional intelligence see Mayer \& Salovey, 1997) and then to regulate, manage, and repair those emotions to accomplish goals (e.g., emotional regulation; see Thompson, 1994). Due to the intense emotional experiences characteristic of adolescence, and adolescents' newly emerging emotional management skills (Silk, Steinberg, \& Morris, 2003; Spear, 2000), adolescents are likely just beginning to learn forgiveness through empathic and affective avenues. In addition, given research indicating the importance of a close parent-child bond in the development of adolescents' emotional regulation abilities (Morris et al., 2007), the parent-child relationship may play a role in adolescents' learning to regulate emotions. Surprisingly, no research has examined adolescent emotional regulation as a direct correlate and mediator of adolescent forgiveness.

\section{Mother-Father differences}

Existing literature is inconsistent regarding differential influences on forgiveness as a function of the gender of the parent. For example, one study reported dyadic differences in forgiveness (Maio et al., 2008), but research by Hoyt et al. (2005) revealed mixed results on whether adolescent children differentiated forgiveness toward mothers and fathers. Despite the inconsistencies in forgiveness research, previous work on parenting has indicated that adolescents report different perceptions of their relationships with mothers and fathers and that mothers and fathers approach the parenting of adolescents differently (Steinberg \& Silk, 2002). Also, previous work with adolescents has indicated that mothers may be more salient for adolescents' positive outcomes (Day \& Padilla-Walker, 2009). Work is needed to determine how the motherand father-child relationships are differentially related to adolescent forgiveness.

\section{Summary and study directions}

Taken together, learning to forgive during adolescence may be critical to the relational and psychological well-being of adolescents as they grow and mature (Paleari et al., 2003; Witvliet et al., 2001). During the time of increased conflict with parents, adolescents may be especially primed to learn to be forgiving and experience more positive and healthy relationships (Paleari et al., 2003). Unfortunately, the understanding of how forgiveness operates within the parent-adolescent relationship is limited and inconsistent. However, a social-psychological framework can be used as a basis for understanding forgiveness within the parent-child relationship (McCullough et al., 1998). Employing four reporters (mother, father, child, and in-home observations), this study will examine the direct and indirect associations of parent-child relationship quality and modeled marital forgiveness with the adolescent's subsequent forgiveness of each parent. These variables are expected to be positively related to parental forgiveness of the child, as well as the social-cognitive skills of empathy and emotional regulation in the adolescent (Maio et al., 2008; Paleari et al., 2003). Parents' forgiveness of the child and adolescents' social-cognitive skills are then expected to be associated with adolescents' forgiveness of mother and father. Direct effects of the parent-child relationship will also be tested, but it is difficult to make specific hypotheses given the dearth of research on this topic during adolescence (Paleari et al., 2003).

\section{Method}

\section{Participants}

Participants were selected from the Flourishing Families Project, an ongoing, longitudinal study of inner family life involving families with a child between the ages of 10 and 12 at Time 1 ( $M$ age of child $=11.24,51 \%$ male). In terms of ethnicity, 76\% of the families were European American, 4\% African American, 1\% Asian, and 19\% of families reported that family members were multi-ethnic. 
In order to study differences in mothers and fathers, this study utilized only two-parent families, making the study sample 334 families from the original 500 family sample. Ninety-five percent of mothers and $93 \%$ of fathers reported being biological parents, $3 \%$ of mothers and $4 \%$ of fathers reported being adoptive parents, and $1 \%$ of mothers and $3 \%$ of fathers reported being step-parents. Four percent of families reported an income less than $\$ 25,000$ per year, $20 \%$ between $\$ 25,000$ and $\$ 50,000$ per year, and $76 \%$ more than $\$ 50,000$ per year. In terms of education, $68 \%$ of mothers and $70 \%$ of fathers reported having a bachelor's degree or higher.

\section{Procedure}

Participant families for the Flourishing Families Project, were selected from a large northwestern city. Families were primarily recruited using a purchased national telephone survey database (Polk Directories/InfoUSA). This database claimed to contain 82 million households across the United States and had detailed information about each household. Families identified using the Polk Directory were randomly selected from targeted census tracts that mirrored the socio-economic and racial stratification of reports of local school districts. All families with a child between the ages of 10 and 14 living within target census tracts were deemed eligible to participate in the study. However, the Polk Directory national database was generated using telephone, magazine, and internet subscription reports; so families of lower socio-economic status were under-represented. Therefore, in an attempt to more closely mirror the demographics of the local area, a limited number of families were recruited into the study through other means (e.g., referrals, fliers; $n=77,15 \%$ ). By broadening our approach, we were able to significantly increase the social-economic and ethnic diversity of the sample (although this is not reflected in the sample used in the current study, due to the focus on two-parent families). Preliminary analyses indicated that recruitment method and ethnicity were not significantly correlated with study variables.

Families were interviewed in their homes during the first eight months of 2007 at Time 1 and during the summer months of 2009 at Time 3. Longitudinal retention of participating families was high (92\%), with only 40 of 500 families not participating at Time 3. Each in-home interview consisted of a 1 hour video and a one-and-one-half-hour self-administered questionnaire for mother, father, and child. The current study employed both observational and questionnaire data. It is important to note that there were very little missing data. As interviewers collected each segment of the in-home interview, questionnaires were screened for missing answers and double marking.

\section{Observational data}

At Time 1, in-home observations of the motherand father-child relationships were videotaped as each dyad completed 25min interaction tasks, following the protocol established by the Iowa State Coding Lab. Each dyad was given a stack of cards with discussion questions and was instructed to discuss the questions one at a time until the timer went off and the interviewer returned. During a dyadic interaction the other parent was completing questionnaires, thus allowing for complete confidentiality and non-collaboration between dyads. After the interview, trained coders watched video tapes of each parentchild dyad and coded the entirety of the dyadic interactions using The Iowa Family Interaction Rating Scales (Melby et al., 1998). Coders were extensively trained and were required to reach a minimum of $80 \%$ inter-rater agreement on a coded task by certified coders at the Iowa Behavioral and Social Science Research Institute. Reliability coding was blindly assigned to a second coder on $25 \%$ of coded tasks.

\section{Measures}

\section{Parent-child relationship quality}

The quality of the parent-child relationship was assessed from two perspectives at Time 1: in-home video observations and parent-reported questionnaires. Two coded observational scales were used. Warmth/support measured the degree to which the focal (mother, father, or child) expressed care and support for the other during interaction. Coders took into account three types of behavior: nonverbal communication, including loving smiles and affectionate touching; supportiveness, such as showing concern, encouraging, or praising the other; and content, such as statements of liking, appreciation, and affirmation. The reciprocate warmth/support scale measured the degree to which the focal added to the warmth and support in the interaction and reciprocated (verbally and nonverbally) warm and supportive behavior occurring within the dyad. The scale assessed the focal's reciprocation of these behaviors, not the focal's initiated behaviors. Coders rated behaviors on a scale from 1 (not at all characteristic) to 9 (mainly characteristic). Inter-rater reliability kappas ranged from .78 to .84 for the four mother-child interaction scales and from .81 to .90 for the four father-child interaction scales. The four interaction scales for each dyad (observations of warmth/support and reciprocate warmth/support for parent and child) were combined into one composite scale indicative of the warmth in each relationship. Reliability (Cronbach's $\alpha$ ) for these scales was .71 for the mother-child dyad and .60 for the father-child dyad.

Mother and father self-reported connectedness to the child (quality of the parent-child relationship) at Time 1 were assessed using four items from the Social Connectedness Scale (Lee, Draper, \& Lee, 2001). Items were reworded to focus on the parent-child relationship and parents responded on a Likert scale from 1 (disagree) to 6 (agree). Higher scores on items such as "I am able to relate to my child" represented greater perceived connection between the parent and child. For the entire 
scale, reliability (Cronbach's $\alpha$ ) was found to be .94 (Lee et al., 2001), and for this sample and condensed scale it was found to be .78 (mothers) and .83 (fathers).

\section{Forgiveness}

To measure parent-modeled forgiveness, parents responded to 12 questions proposed by McCullough et al. (1998). Likert response categories ranged from 1 (not at all true) to 7 (very true). Subscales were used to determine forgiveness within the marital dyad as well as forgiveness from parent to child. At Time 1, each parent responded to questions about their spouse such as, "He/she can give up the hurt and resentment toward me." Higher scores were indicative of greater perceived forgiveness from the spouse to the respondent. At Time 3, parents responded to the same questions about their child (e.g., "I can forgive him/her pretty easily"). Higher scores indicated greater forgiveness from parent to child. Previously, the reliability coefficient was found to be .88 (McCullough et al., 1998). Reliability tests for this sample indicated a Cronbach's alpha of .92 (mother perception of forgiveness from spouse at Time 1), .89 (father perception of forgiveness from spouse at Time 1), .82 (mother-reported forgiveness of child at Time 3), and .83 (father-reported forgiveness of child at Time 3). The adolescent's forgiveness of each parent was assessed at Time 3 using the same scale used to assess parental forgiveness, with adolescents responding to questions for mother and father separately, including, "I can forgive him/her pretty easily." Cronbach's alpha was .88 for mothers and .87 for fathers. As expected with an adolescent reporting on the same construct for mother and father, forgiveness toward mother and father were highly correlated (.71).

\section{Social-cognitive skills}

Two measures of social-cognitive functioning were examined at Time 3. The child's empathy was assessed via self-reports using a 7-item measure (Davis, 1983). Respondents answered how much they agreed or disagreed with statements, such as, "When I see someone being taken advantage of, I feel kind of protective toward them," on a scale from 1 (strongly disagree) to 5 (strongly agree). After reverse coding negatively worded items, higher scores indicated greater empathy. Previous reliability for this measure was found to be .72 (Davis, 1983) and was .80 for this research sample.

The adolescent's emotion regulation abilities were also assessed at Time 3 using the 5-item self-report emotional regulation subscale of the Novak and Clayton (2001) self-regulation measure. Adolescents responded to how much they agreed with statements such as, "I have a hard time controlling my temper," and, "I get so frustrated I feel ready to explode," using a scale from 1 (never true) to 5 (always true). After reverse coding all items, higher scores represented the child's ability to better regulate emotions. Cronbach's alpha for previous samples was .95 (Novak \& Clayton, 2001) and was .82 for this sample.

\section{Results}

\section{Descriptive statistics and correlations}

Means and standard deviations for all variables are reported in Table 1. A multivariate analysis of variance (MANOVA) indicated that no study variables significantly differed as a function of ethnicity. However, a MANOVA did indicate significant differences by child gender, Wilk's $\Lambda=.84 ; F(12,252)=4.14, p=.0001$. As follow-up tests to the MANOVA, univariate analyses of variance (ANOVAs) were conducted (see Table 1). Girls reported higher levels of empathy, whereas boys reported higher levels of emotional regulation. Compared to boys, girls also reported more forgiveness toward their fathers and had higher mean scores of observed warmth in the mother-child relationship. Differences by child gender in all other study variables were not significant. Because parent variables are separate for mothers and fathers, $t$-tests were conducted to determine differences in study variables by parent gender. Results revealed that mothers reported higher levels of connectedness, $M=5.33$ vs. $5.11, t=3.70, p=.000$, and greater levels of observed warmth with the adolescent child at Time $1, M=3.02 \mathrm{vs}$.

Table 1

Mean Differences in Study Variables as a Function of Gender of Child $(N=334)$.

\begin{tabular}{|c|c|c|c|c|}
\hline & Total Sample & Males & Females & \\
\hline Variable: & $M(S D)$ & $M(S D)$ & $M(S D)$ & F-value \\
\hline M-C Connectedness (MR) & $5.33(.78)$ & $5.30(.71)$ & $5.36(.85)$ & .380 \\
\hline F-C Connectedness (FR) & $5.11(.89)$ & $5.05(.89)$ & $5.18(.88)$ & 1.54 \\
\hline M-C Warmth (OR) & $3.03(.86)$ & $2.90(.71)$ & $3.15(.98)$ & $5.79^{*}$ \\
\hline F-C Warmth (OR) & $2.85(.79)$ & $2.76(.72)$ & $2.94(.85)$ & 3.79 \\
\hline M Forgiveness of $F(F R)$ & $5.28(1.30)$ & $5.23(1.30)$ & $5.32(1.31)$ & .316 \\
\hline F Forgiveness of M (MR) & $5.51(1.36)$ & $5.42(1.38)$ & $5.60(1.33)$ & 1.27 \\
\hline M Forgiveness of C (MR) & $6.33(.76)$ & $6.30(.79)$ & $6.37(.73)$ & .694 \\
\hline F Forgiveness of C (FR) & $6.09(.91)$ & $6.01(.93)$ & $6.18(.90)$ & 2.28 \\
\hline Empathy (CR) & $3.71(.63)$ & $3.50(.60)$ & $3.93(.57)$ & $34.95^{* * *}$ \\
\hline Emotional Regulation (CR) & $3.97(.67)$ & $4.06(.63)$ & $3.88(.70)$ & $4.68^{*}$ \\
\hline C Forgiveness of M (CR) & $5.43(1.31)$ & $5.28(1.30)$ & $5.57(1.32)$ & 3.25 \\
\hline$C$ Forgiveness of $F(C R)$ & $5.49(1.23)$ & $5.32(1.17)$ & $5.66(1.26)$ & $5.20 *$ \\
\hline
\end{tabular}

Note. $\mathrm{MR}=$ mother report, $\mathrm{FR}=$ father report, $\mathrm{OR}=$ observational report, $\mathrm{CR}=$ child-report.

$* p<.05, * * p<.01, * * * p<.001$. 
$2.85, t=3.05, p=.002$, as well as higher levels of forgiveness toward the child at Time $3, M=6.33$ vs. $6.10, t=3.58, p=.000$, than did fathers. Fathers were perceived by mothers as having higher levels of forgiveness within the marital relationship, $M=5.52$ vs. $5.24, t=3.09, p=.002$.

Correlations were conducted to determine the bivariate relations between all variables in the model (see Table 2; to reduce the risk of making a type 1 error, only correlations with a significance level less than .01 were considered significant). Indicators of the parent-child relationship were significantly correlated with one another, with the highest correlation being between the observations of each parent-child dyad $(r=.39)$. Perceptions of parental forgiveness within the marital dyad were also expectedly related $(r=.25)$, as well as mother and father self-reports of connectedness to the child and forgiveness toward the child $(r=.25 ; r=.38)$. Nearly all study variables were significantly correlated with the outcome variable of adolescent forgiveness toward mother, and many with adolescent forgiveness toward father.

\section{Model analyses}

Evaluation of the path model was conducted in AMOS 17.0 (Arbuckle, 2008). First a measurement model was created to ensure that the measured variables loaded appropriately with their respective latent variables. Factor loadings were acceptable, above .58, for each latent variable. Model fit statistics indicated that the model was a good fit for the data. The comparative fit index (CFI) score was .95 (values range from zero to 1.00 with values close to or above .95 considered to be indicative of good fit) and the root mean square error of approximation (RMSEA) was .03 (values below .05 are a good fit, values between .05 and .08 are acknowledged as acceptable model fit; Williams, Eaves, \& Cox, 2002). These analyses of the measurement model indicated that the relationships between variables were appropriate to be tested further in a theoretical model.

The initial evaluation of the theoretical model began with a saturated model linking the six predictor variables (parent and observational reports of the quality of the relationship for each dyad and parent perceptions of spousal forgiveness at Time 1) to the four mediators (parent-reported forgiveness of the child and child-reported empathy and emotional regulation at Time 3 ), and finally to the two outcome variables (adolescent forgiveness toward mother and father at Time 3). Parent forgiveness of the child and social-cognitive mediators were then linked to adolescent forgiveness. Theoretically relevant error terms were allowed to correlate, indicating that these variables were influenced by similar outside sources not accounted for within the model. Although error and latent variable covariances are not shown in Fig. 1 for parsimony, parent reports of connectedness and observational reports of warmth were correlated for the mother-child relationship, $r=.13, p=.012$, and father-child relationship, $r=.12, p=.019$. Additionally, mother and father reports of connectedness, $r=.17, p=.002$, observational reports of warmth in each parent-child dyad, $r=.37, p=.000$, spouse reports of perceived forgiveness within the marital dyad, $r=.25, p=.000$, empathy and emotional regulation, $r=.05$, n.s., and adolescent forgiveness of mother and father, $r=.65, p=.000$, were correlated. The model was an acceptable fit for the data (CFI $=.96$; RMSEA $=.07 ; \chi^{2}=34.90$, $p<.01, d f=14$ ). The model accounted for $21 \%$ of the variance in adolescent forgiveness toward mothers and $24 \%$ toward fathers. Fig. 1 presents standardized coefficients and significance levels for all significant paths; Table 3 presents all direct, indirect, and total effects.

In terms of direct paths, mother-reported connectedness to her adolescent child at Time 1 was directly related to her selfreported forgiveness of the child, $\beta=.20$, and to the adolescent's self-reported forgiveness of the mother at Time $3, \beta=.12$. Father-reported connectedness to his adolescent child at Time 1 was directly related to his forgiveness of the child, $\beta=.34$, and to adolescents' emotional regulation at Time $3, \beta=.16$. Observed warmth in each parent-child dyad was directly related to that same parent's forgiveness of the child at Time 3 (mother, $\beta=.13$; father, $\beta=.12$ ). Observed warmth in the mother-child dyad was also directly related to adolescent empathy at Time $3, \beta=.15$, while observed warmth of father and child was related to adolescent forgiveness of mother at Time $3, \beta=.14$. Perceptions of marital forgiveness at Time 1 were both related to fatherreported forgiveness of the child at Time 3 (mother forgive father, $\beta=.18$; father forgive mother, $\beta=.17$ ). The father's

Table 2

Correlations Between all Study Variables $(N=334)$.

\begin{tabular}{|c|c|c|c|c|c|c|c|c|c|c|c|c|}
\hline & 1 & 2 & 3 & 4 & 5 & 6 & 7 & 8 & 9 & 10 & 11 & 12 \\
\hline 1. M-C Connectedness (MR) & - & & & & & & & & & & & \\
\hline 2. F-C Connectedness (FR) & .20 & - & & & & & & & & & & \\
\hline 3. M-C Warmth (OR) & $.19^{* *}$ & $.17^{* *}$ & - & & & & & & & & & \\
\hline 4. F-C Warmth (OR) & .11 & $.19 * *$ & $.39 * *$ & - & & & & & & & & \\
\hline 5. M Forgiveness of $F(F R)$ & .10 & $.19 * *$ & .01 & .02 & - & & & & & & & \\
\hline 6. F Forgiveness of M (MR) & .10 & .06 & -.01 & -.09 & $.25^{* *}$ & - & & & & & & \\
\hline 7. M Forgiveness of C (MR) & $.25^{* *}$ & $.18^{* *}$ & $.16^{* *}$ & .02 & $.16^{* *}$ & .14 & - & & & & & \\
\hline 8. F Forgiveness of $C(F R)$ & .10 & $.38^{* *}$ & .05 & .15 & $.28^{* *}$ & $.22 * *$ & $.18^{* *}$ & - & & & & \\
\hline 9. Empathy (CR) & .11 & .03 & $.16^{* *}$ & .07 & .12 & .09 & .14 & .08 & - & & & \\
\hline 10. Emotional regulation (CR) & .03 & $.17 * *$ & .02 & .00 & .09 & .06 & .05 & .10 & .06 & - & & \\
\hline 11. C Forgiveness of M (CR) & $.23^{* *}$ & $.18^{* *}$ & $.17^{* *}$ & $.18^{* *}$ & $.18^{* *}$ & .14 & $.22^{* *}$ & .11 & $.34^{* *}$ & $.20^{* *}$ & - & \\
\hline 12. C Forgiveness of $F(C R)$ & $.15^{* *}$ & .14 & .14 & .13 & .09 & $.20^{* *}$ & .14 & .13 & $.38^{* *}$ & $.28 * *$ & $.71 * * *$ & - \\
\hline
\end{tabular}

Note. $\mathrm{MR}=$ mother report, $\mathrm{FR}=$ father report, $\mathrm{OR}=$ observational report, $\mathrm{CR}=$ child-report.

$* * p<.01, * * * p<.001$. 


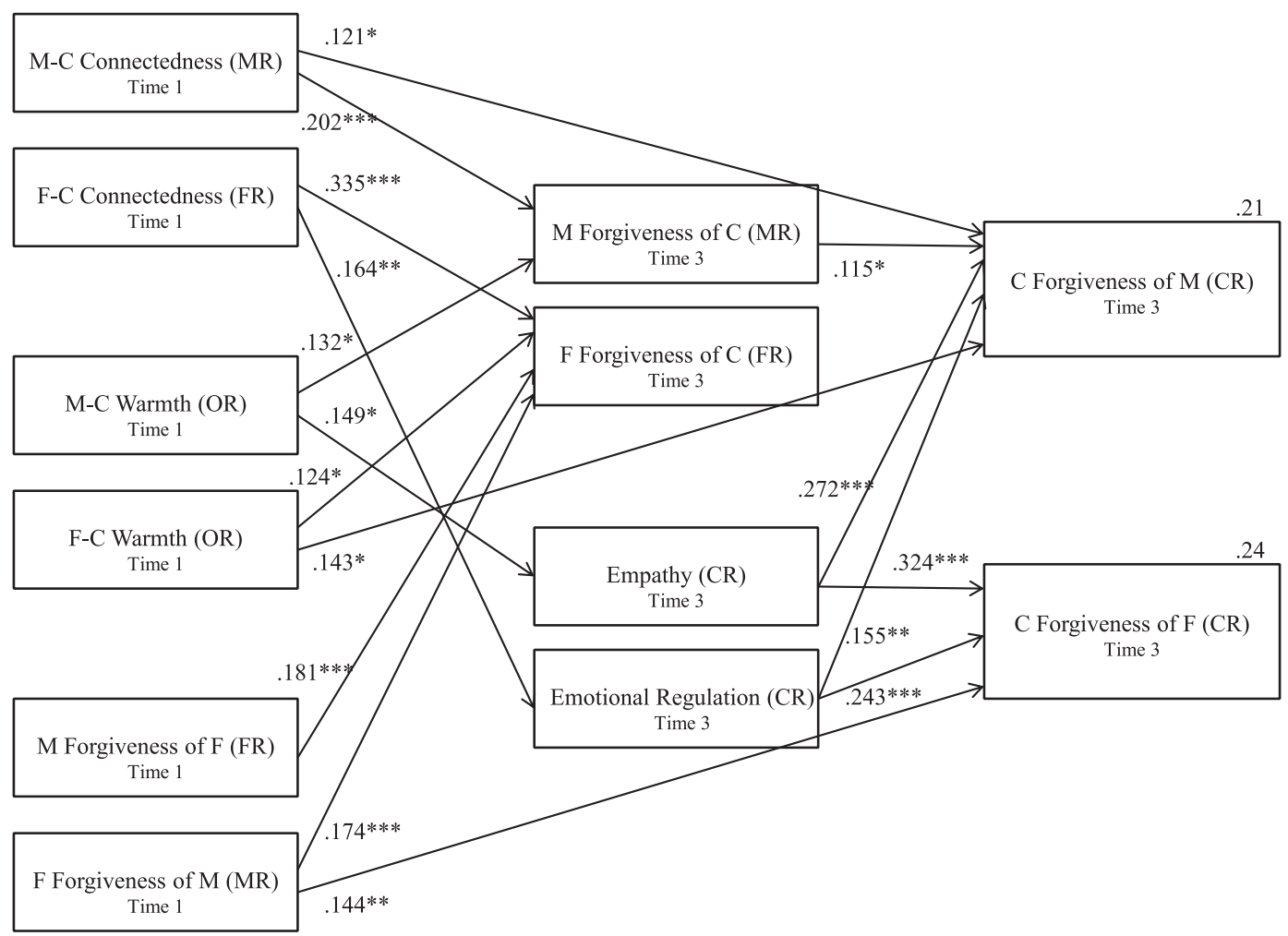

Fig. 1. Parent Forgiveness of Child, Empathy, and Emotional Regulation as Mediators Between Mother and Father-Child Relationship Quality and Marital Forgiveness on Adolescent Forgiveness of Mothers and Fathers. $(N=334)$ Omitted from the figure are non-significant paths and endogenous error correlations. Note. $\mathrm{MR}=$ mother report, $\mathrm{FR}=$ father report, $\mathrm{OR}=$ observational report, $\mathrm{CR}=$ child-report; $\chi^{2}(14)=34.90, p<.01, \mathrm{CFI}=.96, \mathrm{RMSEA}=.07 ;{ }^{*} p<.05,{ }^{*} * p<.01$, $* * * p<.001$.

forgiveness of mother (as perceived by mother) was also directly related to the adolescent child's forgiveness of the father at Time $3, \beta=.14$. Mother forgiveness of the child, $\beta=.12$, adolescent empathy, $\beta=.27$, and adolescent emotional regulation, $\beta=.16$, were also related to adolescent forgiveness of mother, while empathy, $\beta=.32$, and emotional regulation, $\beta=.24$, were related to forgiveness of father.

As seen in Table 3 (representing direct, indirect, and total effects for each variable in the analyses), empathy appears to have the largest total effect upon forgiveness toward mother, $\beta=.27$, and father, $\beta=.32$. For adolescent forgiveness toward mother, the quality of the mother-child relationship appears to have the next largest total effect, $\beta=.16$, followed closely by emotional regulation, $\beta=.16$. Emotional regulation, however, appears to be the second largest total effect, $\beta=.24$, for forgiveness toward father, followed by the quality of the mother-child relationship, $\beta=.10$.

In order to assess indirect or mediation effects Sobel tests were conducted, which provided a direct test of simple mediation by comparing the strength of the indirect effect to the null hypothesis (Preacher \& Hayes, 2004). These tests indicated that observed warmth in the mother-child relationship at Time 1 had a significant indirect link to adolescent forgiveness of both parents at Time 3 via empathy (child forgive mother, $\beta=.04$, Sobel $=2.18, p=.029$; child forgive father, $\beta=.05$, Sobel $=2.24, p=.025$ ) and that father-reported connectedness to the child at Time 1 had a significant indirect link to

Table 3

Decomposition of Effects on Adolescent Forgiveness of Mother/and Father $(N=334)$.

\begin{tabular}{|c|c|c|c|}
\hline Source & Direct & Indirect & Total \\
\hline M-C Connectedness (MR) & $.12 / .07$ & $.04 / .03$ & $.16 / .10$ \\
\hline F-C Connectedness (FR) & $.08 / .04$ & $.01 / .04$ & $.09 / .09$ \\
\hline M-C Warmth (OR) & $.02 / .03$ & $.06 / .05$ & $.08 / .08$ \\
\hline F-C Warmth (OR) & $.14 / .08$ & $-.01 / .00$ & $.13 / .08$ \\
\hline M Forgiveness of $F(F R)$ & $.08 /-.04$ & $.03 / .05$ & $.11 / .01$ \\
\hline F Forgiveness of M (MR) & $.08 / .14$ & $.02 / .04$ & $.10 / .18$ \\
\hline M Forgiveness of C (MR) & $.12 / .02$ & - & $.12 / .02$ \\
\hline F Forgiveness of $\mathrm{C}(\mathrm{FR})$ & $-.06 / .03$ & - & $-.06 / .03$ \\
\hline Empathy (CR) & $.27 / .32$ & - & $.27 / .32$ \\
\hline Emotional Regulation (CR) & $.16 / .24$ & - & $.16 / .24$ \\
\hline
\end{tabular}

Note. $\mathrm{MR}=$ mother report, $\mathrm{FR}=$ father report, $\mathrm{OR}=$ observational report, $\mathrm{CR}=$ child-report. 
adolescent forgiveness of both parents via emotional regulation (child forgive mother, $\beta=.03$, Sobel $=2.04, p=.041$; child forgive father, $\beta=.04$, Sobel $=2.41, p=.016$ ). The indirect paths from Time 1 mother-child relational predictors (connectedness, $\beta=.02$, Sobel $=1.83$, n.s.; observed warmth, $\beta=.02$, Sobel $=1.53$, n.s.) to adolescent forgiveness of the mother at Time 3 were insignificant.

\section{Discussion}

This study provides important insight into the developmental process of forgiveness in parent-child dyads, highlighting factors that are related to adolescents' forgiveness of their mothers and fathers over time. Results from multiple reporters (father, mother, child, and observational reports) indicated that the quality of the mother-child relationship predicted adolescents' level of forgiveness toward mother and father directly, as well as indirectly through the child's own socialcognitive skills (i.e., empathy and emotional regulation). Furthermore, modeling was inconsistently related to adolescent forgiveness and interesting differences in motherand father-child relationships were found.

\section{Parent-child relationship quality as a predictor of adolescent forgiveness}

Current researchers agree that the process and purpose of forgiveness are dependent upon the relational context in which they occur (see Maio et al., 2008; McCullough et al., 1997), although little work has examined the parent-child relationship as it relates to forgiveness. The current study adds to the existing literature by suggesting that forgiveness within the parentchild dyad may operate similarly to other dyadic relationships in that forgiveness is directly related to the quality of the relationship (see Kachadourian et al., 2004). The direct relation of the parent-child relationship with forgiveness may be due to the particular aspects of the relationship that were tapped in the current study, namely warmth and connection. Indeed, Fincham (2000) theorized that it is not empirically justified to assume relationship quality functions the same in all relationships, and that more specific aspects of each relationship type ought to be examined. Connectedness to the child and observed warmth in dyadic interactions may be more strongly related to adolescent forgiveness than variables assessed in previous work, such as commitment, intimacy, trust, and positive relational affect (see Maio et al., 2008; Paleari et al., 2003). Future work should also strive to disentangle the particular aspects of the parent-adolescent relationship that may facilitate greater forgiveness. Given the changing dynamics in the parent-child relationship during adolescence (Steinberg \& Silk, 2002), warmth, autonomy granting, and communication may be particularly salient.

While the quality of the parent-child relationship appears to be directly relevant to adolescent forgiveness, the current study supported the notion that relational variables are often manifest indirectly through more proximal social-cognitive traits (McCullough et al., 1998). As forgiveness is an internal process (Klatt \& Enright, 2009), it is sensible that a close parentchild bond may be necessary, but not sufficient, to lead adolescents to forgive their parents. Rather, the current study suggests that the critical and proximal skills of empathy and emotional regulation must be present, and these can certainly be fostered in parent-child relationships (Carlo, McGinley, Hayes, Batenhorst, \& Wilkinson, 2007; Morris et al., 2007). Indeed, the primary difference in the findings from the current study and work on other close relationships lies in the hierarchical nature of the parent-child relationship. Whereas adults enter relationships with previously developed social-cognitive skills, children learn these skills within the context of the parent-child relationship (Bugental \& Goodnow, 1998). Thus, as youth acquire the necessary social-cognitive skills in the home it may lead not only to increased forgiveness within parent-child relationships, but may also extend to the child's future relationships. This is particularly important during adolescence as children seek greater autonomy from parents and more companionship with peers (Buhrmester, 1996; Steinberg \& Silk, 2002), and as they begin to put into practice the internal working model of relationships learned in the family (Bowlby, 1982).

The current study also provided insight from observed reports of relationship quality, whereas previous studies examining forgiveness within the parent-adolescent relationship only employed questionnaire data (Maio et al., 2008; Paleari et al., 2003). Both parent-reported questionnaires and observational data were significantly associated with parent forgiveness of the child two years later, dispelling the idea that these variables may only be related due to shared method variance. In addition, the observational perspective of the parent-child relationship in this study offers a more complete picture of reality by demonstrating multiple perspectives (Cook \& Goldstein, 1993), and it captures important paths to child forgiveness of the parents that may have been overlooked in previous studies. For example, observed warmth in the mother-child dyad at Time 1 was significantly related to adolescent empathy at Time 3, which in turn was a salient predictor of child forgiveness toward both mother and father. Additionally, observed warmth in the father-child dyad was directly related to child forgiveness of the mother two years later. While questionnaire data offers a helpful starting point, future work needs to continue to employ observational methods to capture different aspects of the motherand father-child relationships.

\section{Parental modeling}

The current study found inconsistent support for the hypothesis that modeled forgiveness is related to adolescent forgiveness. Consistent with family systems theory (Bowen, 1978), marital forgiveness on the part of both mothers and fathers was related to father forgiveness of the child two years later, indicating that positive functioning in the marital dyad may extend to the father-child dyad. This association is especially striking considering the difference in reporters. Fathers' marital forgiveness was also directly related to child forgiveness of the father, suggesting that fathers may play a unique role in 
modeling forgiveness for their children. Additionally, mothers' forgiveness of the child was significantly related to adolescents' returned forgiveness. These findings suggest that children may benefit from seeing parents forgive one another as well as from personally experiencing forgiveness from their parents.

However, modeling variables were not consistently related to adolescent forgiveness, nor were the paths particularly strong, thus raising the question of whether modeling is truly the operative function, as others have claimed (Maio et al., 2008; Murray, 2002). By examining modeled forgiveness along with relationship and social-cognitive variables, the current findings suggest that other relationship and personal variables may be more relevant. For example, mother-child relationship variables and mother forgiveness of the child were particularly salient for adolescent forgiveness of mother, suggesting that the influence of modeled forgiveness from the mother may be more a function of relationship quality rather than modeling. Interestingly, father forgiveness of mother was related to adolescent forgiveness of father. Perhaps adolescents, who feel closely bonded to their mothers are more willing to forgive those who forgive their mothers. This may also demonstrate the importance of the mother-child relationship in adolescent forgiveness. Future work should examine relationship and modeling variables together to determine unique contributions of modeling on adolescents' forgiveness of parents.

Furthermore, modeling occurs when children model behaviors they have seen others do (Eisenberg \& Valiente, 2002), yet forgiveness has been described as a slow process, which is difficult to observe in others (Mullet et al., 2004). Indeed, within the current study, it is assumed that children observe and pay attention to their parents' forgiveness, but this is not explicitly measured. It is possible that adolescents do not specifically recognize forgiveness, but attend only to the general positive quality of their relationship promoted by such forgiveness. Future work should measure adolescents' observation of and attention to their parents' forgiveness to understand if adolescents can observe and then model the forgiveness behavior. In addition, future work should examine the influence of the quality of the marital relationship on adolescent forgiveness to determine if children are positively affected by a general positive atmosphere and if these effects nullify modeling effects.

\section{Social-cognitive mediators}

Social-cognitive skills were found to be consistent predictors of adolescents' forgiveness of both mother and father, providing support for the utility of the social-psychological framework during adolescence (McCullough et al., 1998). As an internal process, it is reasonable that the most salient precursors to forgiveness would be those that occur immediately prior to decision and action. Other studies have similarly hailed the importance of empathy in forgiveness (see Denham et al., 2005; Fincham, 2000; McCullough et al., 1997), but the present study suggests self-regulation plays a critical role for adolescents as well. The passage of time is not enough to constitute true forgiveness, but rather the individual must choose to let go of resentment and let positive emotions toward the offender take center stage (Fincham, 2000). Additionally, forgiveness is not immediately achieved, but rather comes through a process involving concerted effort on behalf of the forgiver (Enright, Santos, \& Al-Mabuk, 1989; Fincham, 2000). The ability to maintain the desire and work required to achieve true forgiveness of others will be aided if the individual is competent at regulating changes in emotions. Future work should include examination of emotional regulation as an important determinant of forgiveness during adolescence.

\section{Gender of parent}

The present findings illustrate that, even in early adolescence, relational and dispositional factors are already functioning to influence the development of forgiveness toward mother and father, and that these associations persist over a two year span. Thus, mothers and fathers are differentially influencing social-cognitive development in their adolescent children (mother was related to empathy, while father was related to self-regulation; Day \& Padilla-Walker, 2009; Padilla-Walker \& Christensen, in press), and mothers and fathers may play important and unique roles in fostering forgiveness within the adolescent relationship.

While both mothers and fathers are important for the development of forgiveness, the current model suggests that the mother-child relationship plays a central role in the adolescent's forgiveness of both mother and father. As seen in Fig. 1, social-cognitive skills are notably related to adolescent forgiveness toward both parents, but all other paths related to adolescent forgiveness encompass some aspect of the mother-child relationship. Previous work has indicated that adolescent motivations for forgiving each parent differ (Hoyt et al., 2005), while this study suggests that the personal relationship with the mother may be most critical for forgiveness of the mother, while social-cognitive skills and the father's forgiveness of mother may be most salient for forgiving the father. Future work should continue to examine both motherand fatheradolescent relationships to determine how mothers and fathers matter uniquely for the development of forgiveness, as well as if adolescents truly forgive each parent differently and why.

\section{Limitations}

Although the current study benefitted from the strength of a longitudinal design, as well as the inclusion of multiple reporters, including observational methods, it was not without limitations. Primarily, the current study only examined twoparent families, but adolescent forgiveness may develop and function differently in single-parent households where economic, social, and relational experiences are unique. Future work should examine how forgiveness operates within these 
homes. Also, the reliability score for the observed warmth within the father-child dyad was relatively low, which might partially explain the lack of significant findings for fathers compared to mothers. Further, this study employed a short and general assessment of forgiveness that may not accurately capture the complexity of forgiveness within these relationships. However, one-item forgiveness measures have been previously found to correlate highly with full and complex forgiveness measures (Subkoviak et al., 1995), and responses to the single item, "I forgive my partner," have been closely aligned with behavioral tendencies (Finkel et al., 2002).

\section{Conclusions}

This longitudinal study offers important insight into the relational and dispositional processes involved in the emergence of forgiveness in adolescents. Similar to work on adult relationships, this study highlights the importance of social-cognitive skills in forgiveness within the parent-child dyad (McCullough et al., 1998), but is the first to demonstrate the salience of emotional regulation for adolescent forgiveness. Further, the present study yielded evidence that such social-cognitive skills provide a way by which parent-child and marital relationships may influence adolescents' forgiveness of their parents. In addition, results highlight the unique roles of mothers and fathers in socializing adolescent forgiveness and suggest that adolescents may be motivated to forgive each parent for different reasons. These findings are particularly salient in consideration of the sensitive developmental time frame of early adolescence, which is a critical time to challenge individuals to use forgiveness to resolve hurts (Enright et al., 1989). The conflict and change that increase in parent-adolescent relationships (Sartor \& Youniss, 2002; Steinberg, 2001), may provide the optimal atmosphere for adolescents to learn what forgiveness means and how to use the skills needed to forgive. Setting patterns of forgiveness during adolescence, when the internal working model of relationships is taking shape (Bowlby, 1982), may set the stage for healthy development and relationships in the future. In this way, adolescents may continue to benefit from a dispositional forgiveness in their future relationships and in their own psychological and emotional well-being (Paleari et al., 2003; Witvliet et al., 2001). Thus, it is critical to continue to examine how parents socialize and influence the development of forgiveness in their adolescent children.

\section{Acknowledgements}

We thank the Family Studies Center at BYU, the School of Family Life, and the College of Family Home and Social Science at BYU, and we recognize the generous support of the many private donors who provided support for this project. We also thank those families who were willing to spend valuable hours with our team in interviews, and the many students who assisted in conducting the interviews.

\section{References}

Arbuckle, J. L. (2008). AMOS 17.0 user's guide. Chicago: SPSS Inc.

Bandura, A. (1986). Social foundations of thought and action: A social cognitive theory. Englewood Cliffs, NJ: Prentice-Hall Inc.

Bowlby, J. (1982). Attachment and loss (2nd ed.). In Attachment, Vol. 1 New York: Basic. Original work published 1969.

Bowen, M. (1978). Family therapy in clinical practice. New York: Jason Aronson.

Bugental, D. B., \& Goodnow, J. J. (1998). Socialization processes. In N. Eisenberg (Ed.), Handbook of child psychology (3rd ed)Social, emotional, and personality development, Vol. 3 (pp. 389-462). Hoboken, NJ: John Wiley \& Sons Inc.

Buhrmester, D. (1996). Need fulfillment, interpersonal competence, and the developmental contexts of early adolescent friendship. In W. Bukowski, A. Newcomb, \& W. Hartup (Eds.), The company they keep (pp. 158-185). New York: Cambridge University Press.

Carlo, G., McGinley, M., Hayes, R., Batenhorst, C., \& Wilkinson, J. (2007). Parenting styles or practices? Parenting, sympathy, and prosocial behaviors among adolescents. Journal of Genetic Psychology, 168, 147-176.

Conger, R., Neppl, T., Kim, K., \& Scaramella, L. (2003). Angry and aggressive behavior across three generations: a prospective, longitudinal study of parents and children. Journal of Abnormal Child Psychology: An Official Publication of the International Society for Research in Child and Adolescent Psychopathology, $31,143-160$.

Cook, W. L., \& Goldstein, M. J. (1993). Multiple perspectives of family relationships: a latent variables model. Child Development, 64, $1377-1388$.

Davis, M. H. (1983). The effects of dispositional empathy on emotional reactions and helping: a multidimensional approach. Journal of Personality, 51, $167-184$.

Day, R. A., \& Padilla-Walker, L. M. (2009). Mother and father connectedness and involvement during early adolescence. Journal of Family Psychology, 23, 900-904.

Denham, S. A., Neal, K., Wilson, B. J., Pickering, S., \& Boyatsis, C. J. (2005). Emotional development and forgiveness in children. In E. L. Worthington (Ed.), Handbook of forgiveness (pp. 127-142). New York: Routledge.

Eisenberg, N., \& Fabes, R. (1998). Prosocial development. Handbook of child psychology, Vol. 3. Social, emotional, and personality development (5th ed.) Hoboken, NJ: John Wiley \& Sons Inc. 701-778.

Eisenberg, N., Fabes, R. A., \& Spinrad, T. L. (2006). Prosocial development. In W. Damon, \& R. M. Lerner (Eds.), Handbook of child psychology (6th ed.)Social, emotional, and personality development, Vol. 3 (pp. 646-718) New York: Wiley.

Eisenberg, N., \& Valiente, C. (2002). Parenting and children's prosocial and moral development. In M. H. Bornstein (Ed.), Handbook of parenting (2nd ed) Practical issues in parenting, Vol. 5 (pp. 111-142). Mahwah, NJ: Lawrence Erlbaum.

Enright, R., \& Fitzgibbons, R. (2000). Helping clients forgive: An empirical guide for resolving anger and restoring hope. Washington, D.C.: American Psychological Association.

Enright, R., Freedman, S., \& Rique, J. (1998). The psychology of interpersonal forgiveness. In R. D. Enright, \& J. North (Eds.), Exploring forgiveness (pp. 46-62). Madison, WI: University of Wisconsin Press.

Enright, R., Santos, M., \& Al-Mabuk, R. (1989). The adolescent as forgiver. Journal of Adolescence, 12, 95-110.

Fincham, F. D. (2000). The kiss of the porcupines: from attributing responsibility to forgiving. Personal Relationships, 7, 1-23.

Finkel, E., Rusbult, C., Kumashiro, M., \& Hannon, P. (2002). Dealing with betrayal in close relationships: Does commitment promote forgiveness. Journal of Personality and Social Psychology, 82, 956-974.

Fow, N. (1996). The phenomenology of forgiveness and reconciliation. Journal of Phenomenological Psychology, 27, 219-233. 
Gold, G., \& Davis, J. (2005). Psychological determinants of forgiveness: an evolutionary perspective. Humboldt Journal of Social Relations, 29, 111-134.

Gordon, K., Hughes, F., Tomcik, N., Dixon, L., \& Litzinger, S. (2009). Widening spheres of impact: the role of forgiveness in marital and family functioning. Journal of Family Psychology, 23, 1-13.

Hodgson, L., \& Wertheim, E. (2007). Does good emotion management aid forgiving? Multiple dimensions of empathy, emotion management and forgiveness of self and others. Journal of Social and Personal Relationships, 24, 931-949.

Hoffman, M. L. (2001). Toward a comprehensive empathy-based theory of prosocial moral development. In A. C. Bohart, \& D. J. Stipek (Eds.), Constructive and destructive behavior: Implications for family, school, and society (pp. 61-86). Washington, DC: American Psychological Association.

Hoyt, W., Fincham, F., McCullough, M., Maio, G., \& Davila, J. (2005). Responses to interpersonal transgressions in families: Forgivingness, forgivability, and relationship-specific effects. Journal of Personality and Social Psychology, 89, 375-394.

Kachadourian, L., Fincham, F., \& Davila, J. (2004). The tendency to forgive in dating and married couples: the role of attachment and relationship satisfaction. Personal Relationships, 11, 373-393.

Klatt, J., \& Enright, R. (2009). Investigating the place of forgiveness within the Positive Youth Development paradigm. Journal of Moral Education, 38, 35-52.

Lee, R. M., Draper, M., \& Lee, S. (2001). Social connectedness, dysfunctional interpersonal behaviors, and psychological distress: testing a mediator model. Journal of Counseling Psychology, 48, 310-318.

Maio, G., Thomas, G., Fincham, F., \& Carnelley, K. (2008). Unraveling the role of forgiveness in family relationships. Journal of Personality and Social Psychology, 94, 307-319.

Malcolm, W., \& Greenberg, L. (2000). Forgiveness as a process of change in individual psychotherapy. In M. E. McCullough, K. I. Pargament, \& C. E. Thoresen (Eds.), Forgiveness: Theory, research, and practice (pp. 179-202). New York: Guilford.

Mayer, J., \& Salovey, P. (1997). What is emotional intelligence. In P. Salovey, \& D. J. Sluyter (Eds.), Emotional development and emotional intelligence: Educational implications (pp. 3-34). New York: Basic Books.

Melby, J., Conger, R., Book, R., Rueter, M., Lucy, L., Repinski, D., et al. (1998). The Iowa family interaction rating scales. In P. Kerig, \& K. Lindahl (Eds.), Family observational coding systems: Resources for systematic research (5th ed) (pp. 1-351). Mahwah, NJ: Lawrence Erlbaum.

McCullough, M. E., Sandage, S. J., Brown, S. W., Rachel, K. C., Worthington, E. L., \& Hight, T. L. (1998). Interpersonal forgiving in close relationships II: theoretical elaboration and measurement. Journal of Personality and Social Psychology, 75, 1586-1603.

McCullough, M., \& Witvliet, C. (2002). The psychology of forgiveness. In C. R. Snyder, \& S. J. Lopez (Eds.), Handbook of positive psychology (pp. 446-458). New York: Oxford University Press.

McCullough, M., \& Worthington, E. (1994). Models of interpersonal forgiveness and their applications to counseling: review and critique. Counseling and Values, 39, 2-14.

McCullough, M., Worthington, E., \& Rachal, K. (1997). Interpersonal forgiving in close relationships. Journal of Personality and Social Psychology, 73, 321-336.

Morris, A., Silk, J., Steinberg, L., Myers, S., \& Robinson, L. (2007). The role of the family context in the development of emotion regulation. Social Development, $16,361-388$

Mullet, E., Girard, M., \& Bakhshi, P. (2004). Conceptualizations of forgiveness. European Psychologist, 9, 78-86.

Murray, R. (2002). The therapeutic use of forgiveness in healing intergenerational pain. Counseling and Values, 46, 188-198.

Novak, S. P., \& Clayton, R. R. (2001). The influence of school environment and self-regulation on transitions between stages of cigarette smoking: a multilevel analysis. Health Psychology, 20, 196-207.

Padilla-Walker, L. M., \& Christensen, K. J. (in press). Empathy and self-regulation as mediators between parenting and adolescents' prosocial behaviors toward strangers, friends, and family. Journal of Research on Adolescence.

Paleari, F., Regalia, C., \& Fincham, F. (2003). Adolescents' willingness to forgive their parents: an empirical model. Parenting: Science and Practice, 3, 155-174.

Preacher, K. J., \& Hayes, A. F. (2004). SPSS and SAS procedures for estimating indirect effects in simple mediation models. Behavior Research Methods, Instruments, $\mathcal{E}$ Computers, 36, 717-731.

Rizkalla, L., Wertheim, E., \& Hodgson, L. (2008). The roles of emotion management and perspective taking in individuals' conflict management styles and disposition to forgive. Journal of Research in Personality, 42, 1594-1601.

Rye, M., \& Pargament, K. (2002). Forgiveness and romantic relationships in college: can it heal the wounded heart. Journal of Clinical Psychology, 58, 419-441.

Sartor, C. E., \& Youniss, J. (2002). The relationship between positive parental involvement and identity achievement during adolescence. Adolescence, 37, $221-234$.

Sastre, M., Vinsonneau, G., Neto, F., Girard, M., \& Mullet, E. (2003). Forgivingness and satisfaction with life. Journal of Happiness Studies, 4, $323-335$.

Silk, J. S., Steinberg, L., \& Morris, A. S. (2003). Adolescents' emotion regulation in daily life: Links to depressive symptoms and problem behavior. Child Development, 74, 1869-1880.

Spear, L. P. (2000). The adolescent brain and age-related behavioral manifestations. Neuroscience and Biobehavioral Reviews, $24,417-463$.

Steinberg, L. (2001). We know some things: parent-adolescent relationships in retrospect and prospect. Journal of Research on Adolescence, 11, 1-19.

Steinberg, L., \& Silk, J. (2002). Parenting adolescents. In M. H. Bornstein (Ed.), Handbook of parenting (2nd ed.)Children and parenting, Vol. 1 (pp. 103-133) Mahwah, NJ: Lawrence Erlbaum.

Subkoviak, M., Enright, R., Wu, C.-R., Gassin, E., Freedman, S., Olson, L., et al. (1995). Measuring interpersonal forgiveness in late adolescence and middle adulthood. Journal of Adolescence, 18, 641-655.

Thompson, R. A. (1994). Emotion regulation: a theme in search of definition. Monographs of the Society for Research in Child Development, 59, 25-52.

Williams, T. O., Jr., Eaves, R. C., \& Cox, C. (2002). Confirmatory factor analysis of an instrument designed to measure affective and cognitive arousal. Educational and Psychological Measurement, 62, 264-283.

Witvliet, C., Ludwig, T., \& Van der Laan, K. (2001). Granting forgiveness or harboring grudges: Implications for emotion, physiology, and health. Psychological Science, $12,117-123$ 